\title{
Penentuan Pola Pembelian Obat Pada Apotek Metro Medika Center Pejaten Barat
}

\author{
Feronikawati Lasmaria Sitorus ${ }^{1}$, Agus Salim ${ }^{2}$ \\ ${ }^{1}$ STMIK Nusa Mandiri, Sistem Informasi \\ feronikasitorus0@gmail.com \\ ${ }^{2}$ Universitas Bina Sarana Informatika, Sistem Informasi \\ agus.salim@bsi.ac.id
}

\begin{abstract}
Abatrak - Dalam dunia bisnis, data merupakan suatu informasi yang sangat penting bagi perusahaan guna untuk memperluas dan mengembangkan ruang bisnisnya. Dunia bisnis khususnya tempat kesehatan seperti Apotek, Klinik, dan Rumah Sakit dituntut agar dapat mengembangkan dan meningkatkan strategi bisnisnya dalam penjualan obat. Apotek Metro Medika Center adalah Apotek yang terletak di Pejaten Barat yang masih menggunakan cara manual, dengan setiap transaksi harus ditulis ke dalam buku besar, ini menyebabkan kesulitan karena begitu banyak data transaksi yang ada dan akan sulit untuk mencari data yang sebelumnya, dan akan ada kemungkinan data tersebut hilang karena masih manual. Dengan perkembangan teknologi maka dibutuhkan pengolahan data yang besar dengan menggunakan Data Mining dengan metode Asosiasi. Penelitian ini dilakukan dengan menerapkan algoritma apriori dengan melihat obat/item yang memenuhi minimum support dan minimum confidence. Data mining menghasilkan aturan asosiasi antar item pada bulan Januari 2019 sampai dengan Desember 2019, diketahui pola penjualan obat Jika membeli PARACETAMOL, maka akan membeli AMOXICILLIN dan PONSTAN dengan nilai support 33\% dan nilai confidence $66,67 \%$.
\end{abstract}

\section{Kata Kunci :Penjualan Obat, Data Mining, Metode Algoritma Apriori}

\begin{abstract}
In the business world, data is very important information company in order to expand and develop its business space. The business world, especially health places such as pharmacies, clinics, and hospitals are demanded to be able to develop and improve their business strategies in drug sales. Pharmacy Metro Medica Center is a Pharmacy located in West Pejaten that still uses manual methods, with each transaction must be written in a ledger, this causes difficulties because so much transaction data exists and it will be difficult to find previous data, and there will be a possibility the data is lost because it is still manual. With the development of technology, it is necessary to process large data by using Data Mining with the Association method. This research was conducted by applying a priori algorithm by looking at drugs / items that meet the minimum support and minimum confidence. Data mining produces association rules between items in January 2019 until December 2019, known patterns of drug sales. If you buy PARACETAMOL, you will buy AMOXICILLIN and PONSTAN with a support value of $33 \%$ and a confidence value of $66.67 \%$.
\end{abstract}

Key Word: Data Mining, Association, Apriori Algorithm, Drug Sales

\section{PENDAHULUAN}

Dalam dunia bisnis, informasi yang sangat penting bagi perusahaan guna untuk memperluas dan mengembangkan ruang bisnisnya adalah suatu data. Cara untuk memperluas ruang bisnis suatu perusahaan, dapat dilakukan dengan meningkatkan dan memaksimalkan kualitas sebuah produk. Dunia bisnis khususnya tempat kesehatan seperti Apotek, Klinik, dan Rumah Sakit dituntut agar dapat mengembangkan dan meningkatkan strategi bisnisnya dalam penjualan obat. Salah satu strategi yang harus dilakukan adalah dengan pelayanan yang baik bagi konsumen seperti menyediakan stok obat agar tidak terjadi kehabisan stok obat yang sering dibeli konsumen dan obat yang dijual tidak mendekati tanggal kadaluwarsa (Salamah \& Ulinnnuha, 2017).
Apotek Metro Medika Center merupakan salah satu apotek yang ada di Pasar Minggu khususnya di Jalan Pejaten Barat. Apotek Metro Medika Center adalah apotek yang menjual berbagai macam obat yang dibutuhkan konsumen. Sistem yang digunakan untuk penjualan obat atau transaksi obat di Apotek Metromedika Center masih secara manual yaitu menggunakan buku tulis besar untuk mencatat obat yang terjual dan semua transaksi setiap harinya akan ditulis pada buku besar tersebut. Ini menyebabkan terlalu banyaknya data-data transaksi setiap harinya dan mungkin saja data itu hilang karena banyak faktor. Pada penelitian ini akan dijelaskan tentang implementasi Data Mining dengan metode Algoritma Apriori pada data transaksi penjualan obat di Apotek Metro Medika Center. 


\section{METODOLOGI PENELITIAN}

Metode yang digunakan dalam penelitian ini adalah penerapan data mining pada penjualan obat dengan menggunakan algoritma apriori. Untuk mengetahui pola kombinasi item dan itemset frekuensi tinggi sehingga dapat dijadikan sebagai faktor pengambilan keputusan dalam memprediksi persedian obat pada Apotek.

Menurut Pramudiono, Data Mining adalah analisis data yang berskala besar atau kompleks dengan tujuan untuk menemukan pola atau kecenderungan yang penting yang biasanya tidak disadari keberadaanya. Menurut Larose Data Mining merupakan sebuah cara yang menggunakan teknik perhitungan matematika, teknik dari pembelajaran mesin, pengenalan pola, statistic, dan visualisasi untuk penanganan permasalahan pengambilan informasi dari kumpulan data yang besar (Novriansyah \& Nurcahyo, 2019).

Data Mining juga dapat diartikan sebagai proses menggali atau penambangan data yang menghasilkan sebuah output (keluaran) berupa pengetahuan atau informasi.

\section{Pengelompokan Data Mining}

Data mining dibagi menjadi beberapa kelompok berdasarkan tugas atau pekerjaan yang dapat dilakukan (Buulolo, 2020), yaitu :

a. Deskripsi (Description)

Deskripsi dari pola kecenderungan sering memberi penjelasan untuk suatu pola atau kecenderungan.

b. Estimasi (Estimation)

Model ini dibangun menggunakan baris data (record) lengkap yang menyediakan nilai dari variabel target sebagai nilai prediksi. Selanjutnya , pada peninjauan berikutnya estimasi nilai dari variabel target dibuat berdasarkan nilai variabel prediksi.

c. Prediksi (Prediction)

Prediksi hampir sama dengan klasifikasi dan estimasi, kecuali bahwa dalam nilai dari hasil akan ada di masa mendatang .

d. Klasifikasi (Classification)

Dalam klasifikasi, terdapat target variabel kategori. Sebagai contoh, penggolongan pendapatan dapat dipisahkan dalam tiga kategori, yaitu: pendapatan tinggi, pendapatan sedang, dan pendapatan rendah.

e. Pengklasteran (Clustering)

Pengklasteran merupakan pengelompokan record, pengamatan, atau memperhatikan dan membentuk kelas obyek-obyek yang memiliki kemiripan.

f. Asosiasi (Association)

Asosiasi merupakan teknik untuk menentukan hubungan antar item dalam suatu dataset (sekumpulan data).

\section{Tahap-tahap Data Mining}

Tahap-tahap data mining ada 6 (Putra, Haryanto, \& Dolphina, 2018) yaitu:
1. Pembersihan Data (Data Cleaning)

Pembersihan data adalah proses menghilangkan data yang yang noise seperti duplikasi pada data

2. Integrasi Data (Data Integration)

Integrasi data adalah gabungan dari berbagai data ke dalam suatu basis data yang baru.

\section{Seleksi Data ( Data Selection)}

Pemilihan atribut atau field yang ada pada data set yang dibutuhkan untuk proses lebih lanjut, dimana data akan disimpan terpisah dalam suatu berkas sehingga memudahkan dalam pengelohan data mining.

\section{Proses Mining}

Merupakan proses pencarian pola ataupun informasi yang menarik dalam sebuah kumpulan data yang dipilih, dengan metode tertentu yang cocok.

5. Evaluasi pola (Pattern Evaluation)

Informasi yang terdapat dari sebuah proses data mining harus ditampilkan dalam bentuk yang amat mudah agar dapat dipahami oleh pihak yang akan menggunakannya
6. Presentasi
Presentation)
Pengetahuan
(Knowledge

Presentasi pengetahuan merupakan visualisasi dan penyajian pengetahuan mengenai metode yang digunakan untuk memperoleh pengetahuan yang diterima oleh pengguna.

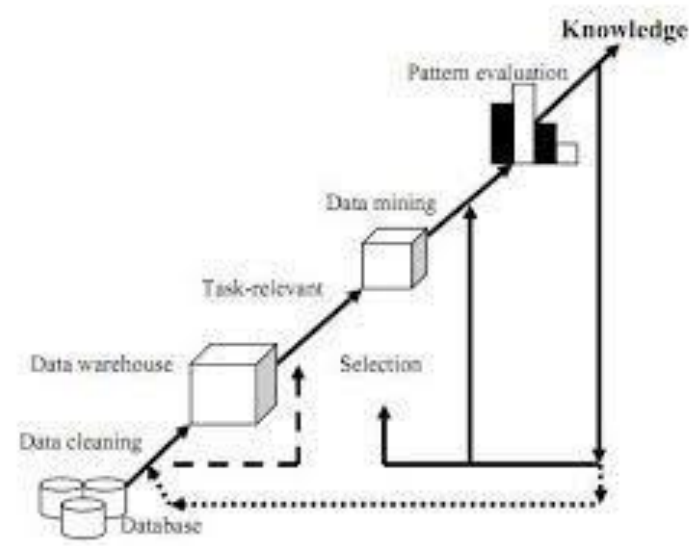

Sumber : (Santoso, Hariyadi, \& Prayitno, 2016) Gambar 1 Tahapan Data Mining

\section{Ukuran Kepercayaan Rule}

Dalam menentukan suatu association rule, terdapat suatu ukuran kepercayaan yang didapat dari hasil pengolahan data dengan perhitungan tertentu. Umumnya ada dua ukuran (Putra et al., 2018), yaitu: 1. Support

Support atau dukungan merupakan suatu ukuran yang menunjukkan seberapa

besar dominasi suatu item dari keseluruhan transaksi. 2. Confidence

Confidence atau tingkat kepercayaan adalah suatu ukuran yang menunjukkan

hubungan item secara conditional, misalnya seberapa sering item B dibeli jika orang membeli item A. 


\begin{abstract}
Algoritma Apriori
Algoritma Apriori adalah salah satu algoritma dalam data mining yang paling terkenal dalam menemukan pola data atau pola kemunculan data. Algoritma Apriori digunakan untuk menemukan pola pembelian pelanggan berdasarkan transaksi pembelian (Buulolo, 2020). Dalam membentuk kandidat itemset ada dua proses yang dapat dilakukan dengan algoritma apriori (Salim \& Nizar, 2020) :
\end{abstract}

a. Join (penggabungan )

Dalam proses ini, setiap item digabungkan dengan item lain sampai tidak dapat terbentuk kombinasi lagi. b. Pruning (pemangkasan)

Pada proses ini, hasil kombinasi item akan

dipangkas berdasarkan minimum support yang telah ditentukan.

\section{Analisis Pola Frekuensi Tinggi dengan Algoritma Apriori}

Mencari kombinasi item yang memenuhi syarat minimum dari nilai support dalam basis data. Nilai support sebuah item diperoleh dengan menggunakan rumus berikut (Muflikhah, Ratnawati, \& Putri, 2018):

$\operatorname{Support}(\mathrm{A})=\frac{\sum \text { Transaksi yang mengandung A }}{\sum \text { Transaksi }} * 100 \%$

Untuk mencari nilai support dari 2 item

menggunakan rumus berikut :

Support $(A, B)=P(A \cap B)$

$(A \cap B)=\frac{\text { Transaksi yang mengandung A dan B }}{\sum \text { Transaksi }} * 100 \% \ldots$

Apabila nilai support sudah tidak memenuhi syarat minimum nilai support yang telah ditentukan pencarian nilai support akan dihentikan. Setelah semua pola frekuensi tinggi ditemukan, barulah dicari aturan asosiasi yang memenuhi syarat minimum untuk confidence dengan menghitung confidence. Aturan asosiasi $\mathrm{A} \rightarrow \mathrm{B}$. Nilai confidence dari aturan $\mathrm{A} \rightarrow \mathrm{B}$ diperoleh dari rumus berikut:

Confidence $=\boldsymbol{P}(\mathbf{B} \mid \mathbf{A})=$ Ltransaksi mengandung $A$ dan $B$ Stransaksi mengandung A $\times 100 \%$

\section{Software}

Dalam menghitung algoritma apriori penulis menggunakan dua software Pendukung yaitu dengan: 1. Tanagra

Tanagra adalah software data mining bersifat gratis untuk tujuan akademik guna memberikan peneliti kemudahan dalam mengolah data mining (Wahyuningtias \& Rusdiansyah, 2019).

2. Microsoft excel 2010

melakukan operasi perhitungan serta dapat mempresentasikan data ke dalam bentuk table (tabel). (Lee, 2016)

\section{Hasil dan Pembahasan}

Dari beragam jenis obat yang ada, penulis hanya menganalisa 20 jenis obat seperti pada tabel 1 :

Tabel 1. Nama obat

\begin{tabular}{ll}
\hline No & Nama Obat \\
1 & SANGOBION \\
2 & MEFINAL \\
3 & ASMET \\
4 & IMBOOTS \\
5 & NEURALGIN \\
6 & AMOXICILLIN \\
7 & PARATUSIN \\
8 & NEUROBION \\
9 & PROMAAG \\
10 & TEMPRA \\
11 & PONSTAN \\
12 & DULCOLAX \\
13 & SANMOL \\
14 & ALLOPURINOL \\
15 & VOLTADEX \\
16 & PROCOLD \\
17 & BISOLVON \\
18 & OBH COMBI \\
9 & METFORMIN \\
20 & PARACETAMOL \\
\hline Sumbr & (SitOIUS \& Salim 2020)
\end{tabular}

Sumber : (Sitorus \& Salim, 2020)

a. Melakukan Pengelompokkan 3 Obat Paling Banyak Terjual, setelah data penjualan obat dalam setahun disusun, tahap selanjutnya akan terbentuk pola transaksi penjualan seperti dalam tabel 2:

Tabel 2. Pola transaksi

\begin{tabular}{ll}
\hline Bulan & Itemset \\
\hline 1 & PONSTAN,OBHCOMBI,AMOXICILLIN \\
2 & ASMET, PONSTAN, OBH COMBI \\
3 & AMOXICILLIN,PONSTAN,PARACETAMOL \\
4 & AMOXICILLIN,PONSTAN,PARACETAMOL \\
5 & AMOXICILLIN, ASMET, PARACETAMOL \\
6 & PARATUSIN, AMOXCILLIN, OBH COMBI \\
7 & AMOXICILLIN,PONSTAN,PARACETAMOL \\
8 & PARATUSIN, AMOXICILLIN, PONSTAN \\
9 & ASMET, PARATUSIN, AMOXICILLIN \\
10 & PARATUSIN,AMOXICILLIN,PARACETAOL \\
11 & PARATUSIN, AMOXICILLIN, PONSTAN \\
12 & AMOXICILLIN, PONSTAN, \\
& PARACETAMOL \\
\hline
\end{tabular}

Sumber : (Sitorus \& Salim, 2020)

b. Pembuatan Format Tabular, Format tabular data transaksi bulanan setelah diolah akan terlihat seperti pada tabel 3:

Tabel 3. Tabulasi Penjualan Obat

\begin{tabular}{ccccccc}
\hline Bulan & Asmet & Paratusin & Amox & Ponstan & Obh & Prctl \\
\hline 1 & 0 & 0 & 1 & 1 & 1 & 0 \\
2 & 1 & 0 & 0 & 1 & 1 & 0 \\
3 & 0 & 0 & 1 & 1 & 0 & 1 \\
4 & 0 & 0 & 1 & 1 & 0 & 1 \\
5 & 1 & 0 & 1 & 0 & 0 & 1 \\
6 & 0 & 1 & 1 & 0 & 1 & 0 \\
7 & 0 & 0 & 1 & 1 & 0 & 1 \\
8 & 0 & 1 & 1 & 1 & 0 & 0 \\
9 & 1 & 1 & 1 & 0 & 0 & 0
\end{tabular}




\begin{tabular}{ccccccc}
10 & 0 & 1 & 1 & 0 & 0 & 1 \\
11 & 0 & 1 & 1 & 1 & 0 & 0 \\
12 & 0 & 0 & 1 & 1 & 0 & 1 \\
Jumlah & $\mathbf{3}$ & $\mathbf{5}$ & $\mathbf{1 1}$ & $\mathbf{8}$ & $\mathbf{3}$ & $\mathbf{6}$ \\
\hline
\end{tabular}

Sumber : (Sitorus \& Salim, 2020)

c. Pembuatan Itemset Proses pembentukan $\mathrm{C} 1$ atau disebut dengan 1 itemset dihitung dengan minimum support $=\mathbf{3 0 \%}$. Adapun hasil yang didapat pada proses pembentukan 1 itemset terlihat pada tabel 4:

Tabel 4. Support 1 itemset

\begin{tabular}{lll}
\hline Itemset & Jumlah & Support \\
\hline ASMET & 3 & $25 \%$ \\
PARATUSIN & 5 & $42 \%$ \\
AMOX & 11 & $92 \%$ \\
PONSTAN & 8 & $67 \%$ \\
OBH & 3 & $25 \%$ \\
PARACETAMOL & 6 & $50 \%$
\end{tabular}

Sumber : (Sitorus \& Salim, 2020)

Dapat diketahui dari table 4, yang memenuhi standar minimum support yaitu pada obat PARATUSIN, AMOXICILLIN PONSTAN, PARACETAMOL.

d. Proses pembentukan C2 atau disebut dengan 2 itemset dihitung dengan minimum support $=$ 30\%. Adapun hasilnya padapembentukan 2 itemset terlihat pada table 5:

Tabel 5. Support 2 itemset

\begin{tabular}{lll}
\hline Nama Obat & Jumlah & Support \\
\hline ASMET, & 1 & $8 \%$ \\
PARATUSIN & & \\
ASMET, AMOX & 2 & $17 \%$ \\
ASMET, & 1 & $8 \%$ \\
PONSTAN & & \\
ASMET, OBH & 1 & $8 \%$ \\
ASMET, PCT ML & 1 & $8 \%$ \\
PARATUSIN, & 5 & $\mathbf{4 2} \%$ \\
AMOX & & \\
PARATUSIN, & 2 & $17 \%$ \\
PONSTAN & & \\
PARATUSIN, & 1 & $8 \%$ \\
OBH & & $8 \%$ \\
PARATUSIN, & 1 & \\
PCT ML & & $\mathbf{5 8} \%$ \\
AMOX, & 7 & \\
PONSTAN & & $\mathbf{5 0} \%$ \\
AMOX, OBH & 2 & $2 \%$ \\
AMOX, PCT ML & 6 & $\mathbf{3 3} \%$ \\
PONSTAN, OBH & 2 & 0 \\
PONSTAN, PCT & 4 & \\
ML & & \\
OBH, PCT ML & 0 &
\end{tabular}

Sumber : (Sitorus \& Salim, 2020)

Dari tabel 5, Persentase jumlah 2 itemset terpilih hanya kombinasi 2 itemset yang memenuhi syarat minimum support yang ada di dalam data transaksi, yaitu: PARATUSIN \& AMOX, AMOX \& PONSTAN, AMOX \& PCTML, serta PONSTAN \& PCTML. e. Kombinasi 3 Itemset, proses pembentukan C3 atau disebut dengan 3 itemset dihitung dengan minimum Support $=\mathbf{3 0 \%}$. Tabel 6 merupakan hasil dari proses pembentukan 3 itemset yaitu: Tabel 6. Support 3 Itemset

\begin{tabular}{lll} 
Nama Obat & Jumlah & Support \\
\hline $\begin{array}{l}\text { AMOX,PONSTAN, } \\
\text { PCT ML }\end{array}$ & 4 & $\mathbf{3 3 \%}$ \\
$\begin{array}{l}\text { AMOX,PONSTAN, } \\
\text { PARATUSIN }\end{array}$ & 2 & $17 \%$ \\
$\begin{array}{l}\text { AMOX, PCT ML, } \\
\text { PARATUSIN }\end{array}$ & 1 & $8 \%$ \\
$\begin{array}{l}\text { PONSTAN,PCT } \\
\text { ML, PARATUSIN }\end{array}$ & 0 & 0 \\
\hline
\end{tabular}

Sumber : (Sitorus \& Salim, 2020)

f. Pembentukan Aturan Asosiasi.

Berdasarkan proses analisis pola frekuensi tinggi yang telah dilakukan sebelumnya, data hasil penilaian support pada kombinasi 3 itemset diperoleh himpunan = AMOXCILLIN, PONSTAN dan, PARACETAMOL (Tabel 6). Kemudian, karena pada kombinasi 3 itemset hanya diperoleh satu himpunan yang memenuhi persentase diatas minimum support, maka tidak perlu dilakukan pencarian kembali pada kombinasi 4 itemset. Pembentukan aturan asosiasi ini dilakukan dengan menghitung nilai confidence dari aturan asosiatif $\mathrm{A} \rightarrow \mathrm{B}$ yang memenuhi syarat minimum untuk confidence yang telah ditentukan. Minimum confidence ditentukan sebesar $=\mathbf{6 0 \%}$. Nilai confidence yang diperoleh (Tabel 7) adalah berikut ini:

Tabel 7. Nilai Confidence Aturan Asosiatif

\begin{tabular}{llr}
\hline Aturan & \multicolumn{2}{c}{ Confidence } \\
\hline $\begin{array}{l}\text { Jika membeli Amox maka akan } \\
\text { membeli Ponstan dan PCT ML }\end{array}$ & $4 / 11$ & $36 \%$ \\
$\begin{array}{l}\text { Jika membeli Ponstan maka akan } \\
\text { membeli Amox dan PCT ML }\end{array}$ & $4 / 8$ & $50 \%$ \\
Jika membeli PCT ML maka akan & $4 / 6$ & $\mathbf{6 6 \%}$
\end{tabular}

membeli Amox dan Ponstan

Sumber : (Sitorus \& Salim, 2020)

g. Setelah proses pembuatan hitung manual, maka dilakukan proses perhitungan dengan software Tanagra versi 1.4. Dibawah ini merupakan langkahlangkah kerja pengimplementasian pada software Tanagra versi 1.4:

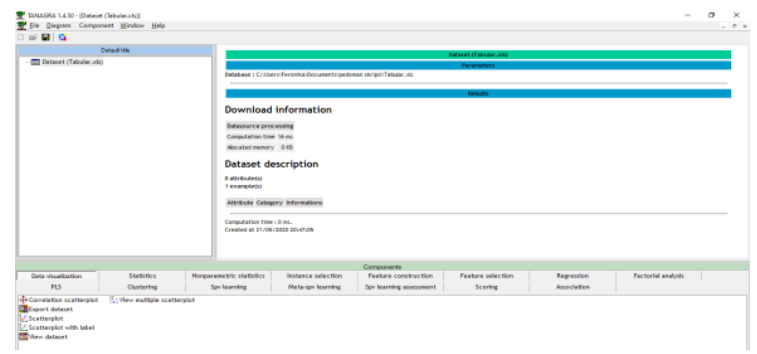

Sumber : (Sitorus \& Salim, 2020)

Gambar 2. Tampilan Aplikasi Terkoneksi

Gambar 2 merupakan visualisasi dari aplikasi Tanagra ketika format tabular data pada tabel 3 
dimasukkan ke dalamnya. Pemberian nilai support dapat dilakukan dengan klik kanan pada Frequent Itemset 1, lalu pilih Parameters.Tampilan Parameters akan muncul untuk memasukkan nilai minimum support sebesar $30 \%$, ditunjukkan oleh gambar 3.

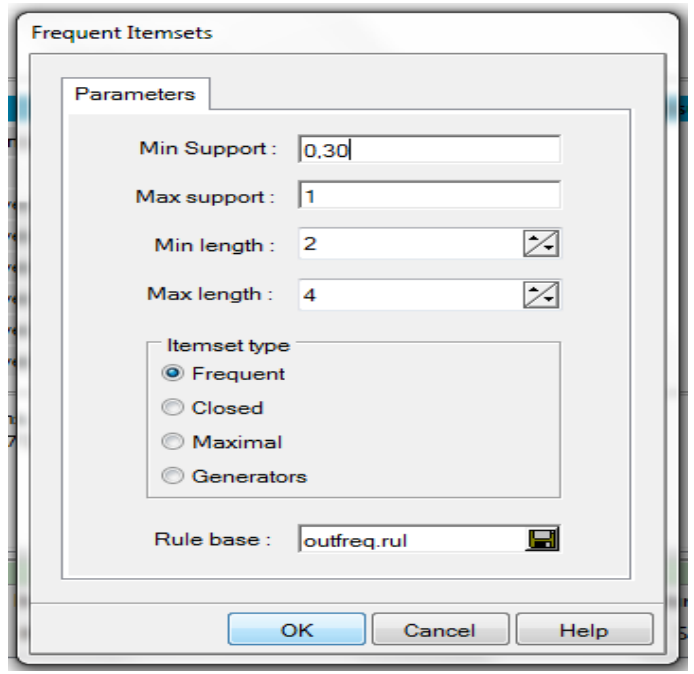

Sumber : (Sitorus \& Salim, 2020)

Gambar 3. Tampilan Input Parameters Frequent Itemset

\begin{tabular}{|c|c|c|}
\hline \multicolumn{3}{|c|}{ ITEMSETS [FP itemsets loaded] } \\
\hline $\mathrm{N}^{*}$ & Descioition & Suppot \\
\hline 1 & 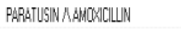 & 41,7 \\
\hline 2 & PARGTUSN & 41,7 \\
\hline 3 & PCT_MLAAMCXXCLUN & 500 \\
\hline 4 & PCT_ML & 5000 \\
\hline 5 & PCT_ML $\triangle$ FONSTAS A AMOXOLLN & 3,3 \\
\hline 6 & PCT_MLAPONSTAN & 30,3 \\
\hline 7 & PONSTAN & 66.7 \\
\hline 8 & PONSTAN AMHCXXCLUN & 583 \\
\hline 9 & AMOXOLLN & 91,7 \\
\hline
\end{tabular}

Sumber : (Sitorus \& Salim, 2020)

Gambar 4. Tampilan Hasil Frequent Itemsets

Gambar 4 diatas merupakan pengujian untuk menghasilkan jenis item dan pola kombinasi dua dan tiga itemset

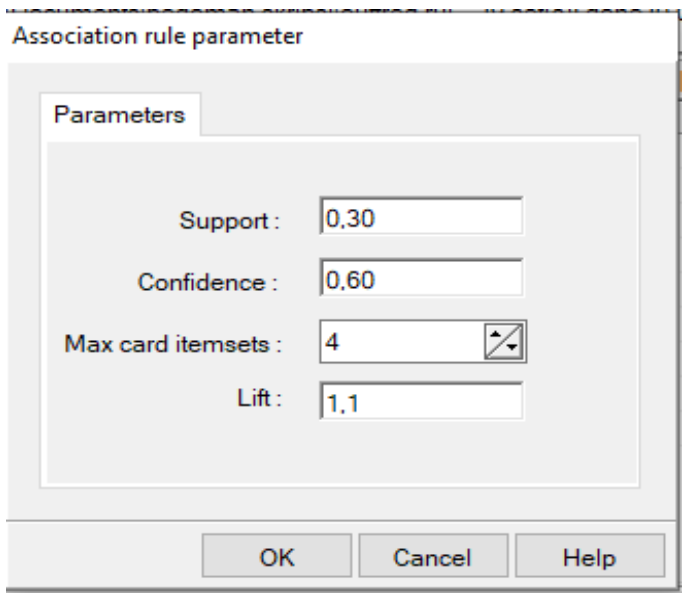

Sumber : (Sitorus \& Salim, 2020)

Gambar 5. Tampilan Association Rule Parameters

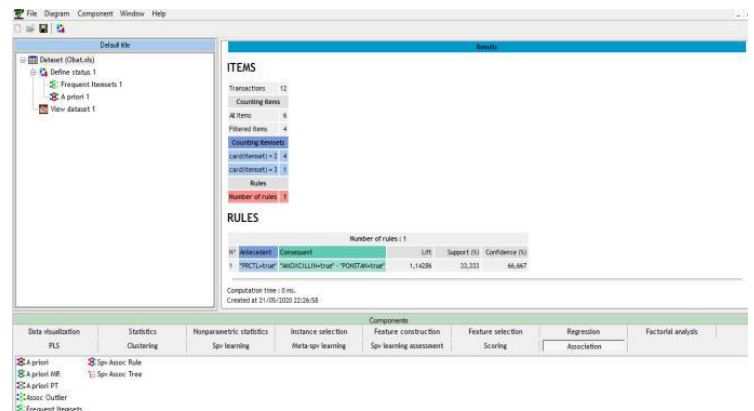

Sumber : (Sitorus \& Salim, 2020)

Gambar 6. Tampilan Hasil Pembentukan Association Rule

Aturan asosiasi final didapatkan dari nilai persentase yang memenuhi dua syarat minimum support dan minimum confidence yang telah ditentukan (gambar 5). Pembentukan rule-nya terlihat pada gambar 6 . Item yang dimaksud terdapat dalam tabel 8 , berikut ini:

Tabel 8. Hasil Final Asosiasi

\begin{tabular}{|c|c|c|}
\hline Aturan & Support & Confidence \\
\hline $\begin{array}{l}\text { Jika membeli PCT ML } \\
\text { maka akan membeli }\end{array}$ & $33 \%$ & $66.67 \%$ \\
\hline
\end{tabular}

Sumber : (Sitorus \& Salim, 2020)

Berdasarkan aturan asosiasi final yang telah dihasilkan diatas, dapat diketahui Obat yang paling banyak terjual pada Apotek Metro Medika Pejaten Barat:

RULES

\begin{tabular}{|c|c|c|c|c|}
\hline \multicolumn{5}{|c|}{ Number of rules: 1} \\
\hline $\mathrm{N}^{*}$ Antecedent & Consequent & Lift & Support (s) & Confidence (*) \\
\hline 1 "PCT ML=true" & " "AMOXICILLIN=true" - "PONSTAN=true" & 1,14286 & 33,333 & 66,667 \\
\hline $\begin{array}{l}\text { Computation time : } \\
\text { Created at } 27 / 05 / 2\end{array}$ & 2020 17:10:08 & & & \\
\hline
\end{tabular}

Sumber : (Sitorus \& Salim, 2020)

Gambar 7. Hasil Akhir dengan Asosiasi Final

\section{KESIMPULAN}

Penjualan obat paling banyak terjual pada Apotek Metro Medika Center dapat diketahui menggunakan Algoritma Apriori, dengan melihat obat atau item yang memenuhi minimum support dan minimum confidence. Obat yang paling banyak terjual adalah PARACETAMOL, AMOXICILLIN dan PONSTAN. Dari aturan asosiasi final yang diketahui Jika membeli PARACETAMOL, maka akan membeli AMOXICILLIN dan PONSTAN dengan nilai support $33 \%$ dan nilai confidence $66,67 \%$.

Algoritma Apriori dapat membantu perusahaan dalam mengembangkan strategi pemasaran dengan promosi dan memberikan informasi untuk 
mengantisipasi kekosongan stok obat dikemudian hari. Dengan menggunakan software Tanagra versi 4.1 dapat membantu mendapat aturan asosiasi final secara otomatis pada pengimplementasi Algoritma Apriori.

\section{Saran}

Setelah penulis menyelesaikan penelitian ini, saran untuk pengembangan pada penelitian selanjutnya adalah:

1. Pengimplementasian data mining diharapkan dapat lebih memperhatikan kualitas dan kuantitas datanya, agar informasi yang dihasilkan dapat terlihat keakurasian sebuah informasi.

2. Dalam penggunaan algoritma Apriori di perlukan pemahaman tentang aturan Asosiasi dan data mining dan cara menjalankan aplikasi software Tangra 1.4.

3. Software yang digunakan untuk mengolah data dalam pembentukan aturan asosiasi final supportconfidence dapat menggunakan software pendukung lainnya, tidak hanya mengandalkan Tanagra saja.

4. Analisa yang telah dilakukan dan hasil pada skripsi ini merupakan analisa mendasar yang perlu dikembangkan lagi. Dapat menggunakan algoritma lain sebagai perbandingan sehingga dapat diketahui bagaimana metode apriori masih dapat digunakan dan diandalkan untuk mencari pola antar item dalam jumlah data yang sangat besar dengan hasil yang lebih baik lagi.

\section{REFERNSI}

Buulolo, E. (2020). Data Mining Untuk Perguruan Tinggi. Yogyakarta: Deepublish.

Lee, C. (2016). Belajar Microsoft Excel-Step by Step. Jakarta: Elex Media Komputindo.

Muflikhah, L., Ratnawati, D. E., \& Putri, R. R. M. (2018). Buku Ajar Data Mining. Malang: Universitas Brawijaya Press.

Novriansyah, D., \& Nurcahyo, G. W. (2019). ALGORITMA DATA MINING DAN PENGUJIAN, " in Algoritma Data Mining dan Pengujian. Yogyakarta: Deepublish.

Putra, A. A. C., Haryanto, H., \& Dolphina, E. (2018). Implementasi Metode Association Rule Mining Dengan Algoritma Apriori Untuk Rekomendasi
Promo Barang. CSRID Journal, 10(2).

Salamah, E. N., \& Ulinnnuha, N. (2017). Analisis Pola Pembelian Obat dan Alat Kesehatan di Klinik Ibu dan Anak Graha Amani dengan Menggunakan Algoritma Apriori. Jurnal INFORM, 2(2), 1-6. https://doi.org/10.25139/ojsinf.v2i1.401

Salim, A., \& Nizar, M. (2020). Application of Apriori Algorithm Method in Sales Analysis of Mountain Bag Brands in Post Stores 1. JITE ( Journal of Informatics and Telecommunication Engineering ), 4(1), 1-10.

Santoso, H., Hariyadi, I. P., \& Prayitno. (2016). DATA MINING ANALISA POLA PEMBELIAN PRODUK DENGAN MENGGUNAKAN METODE ALGORITMA APRIORI. Seminar Nasional Teknologi Informasi Dan Multimedia.

Sitorus, F. L., \& Salim, A. (2020). Laporan Akhir Penelitian: Penentuan Pola Pembelian Obat Pada Apotek Metro Medika Center Pejaten Barat. Jakarta.

Wahyuningtias, Y., \& Rusdiansyah, R. (2019). Analisis Penerapan Asosiasi Untuk Menentukan Transaksi Penjualan Pada What'S Up Café Dengan Metode Algoritma Apriori. Jurnal Riset Informatika, 1(4), 181-186. https://doi.org/10.34288/jri.v1i4.92

\section{PROFIL PENULIS}

\section{Penulis Pertama}

Feronikawati Lasmaria Sitorus, merupakan alumni STMIK Nusa mandiri program studi Sistem Informasi, lulus pada tahun 2020

\section{Penulis kedua}

Agus Salim, memperoleh gelar M.Kom, Jurusan Ilmu Komputer pada STMIK Nusa Mandiri Jakarta, lulus tahun 2010. Saat ini menjadi Dosen di Universitas Bina Sarana Informatika (D3) program studi Sistem Informasi dan Dosen di STMIK Nusa Mandiri Jakarta program studi sistem informasi. 